\title{
THE FATIGUE BEHAVIOUR OF GFRP BARS - EXPERIMENTAL STUDY
}

\author{
Ondřej JAnuŠ ${ }^{a, *}$, FrAntiŠEK GIRGLE $^{a}$, IVA RozSypalová ${ }^{a}$, \\ Vojtěch Kostiha ${ }^{a}$, Lenka Bodnárováa ${ }^{a}$, Petr ŠtěPÁneK ${ }^{a}$, Jan Prokeš ${ }^{b}$ \\ ${ }^{a}$ Brno University of Technology, Faculty of Civil Engineering, Veveři 95, 60200 Brno, Czech Republic \\ ${ }^{b}$ Prefa kompozity, a.s., Kulkova 10/4231, 61500 Brno, Czech Republic \\ * corresponding author: janus.o@fce.vutbr.cz
}

\begin{abstract}
The paper describes an experimental program for studying the fatigue performance of GFRP bars, which has been initiated by the authors. Two different test configurations were used to assess the fatigue behaviour. The bare specimens were tested within the first series. A modified gripping system was used to reduce eccentricity when the bar was not directly fixed. However, the boundary conditions seem to affect the results. The second series consisted of a set of specimens of bars embedded in concrete. This configuration seems appropriate for determination of fatigue life of GFRP bars. Two S-N curves for bare bars and bars embedded in concrete were created and compared. Significant reduction of interlaminar shear strength at the beginning of fatigue loading proved matrix or fibre/matrix interface damage.
\end{abstract}

KEYwords: Composite, cyclic loading, fatigue, GFRP, reinforcement, stiffness, S-N curve.

\section{INTRODUCTION}

At present, many bridge constructions are in a very bad, almost emergency state, and require remediation due to the corrosion of steel reinforcement, which is greatly accelerated by chlorides, moisture and freezing cycles. Composite reinforcement in these application areas appears to be a suitable alternative to steel reinforcement. The suitability of its application is confirmed by many successful applications. However, as the bridge decks are directly subjected to repeated transport loads, the fatigue design is an important and often decisive part of the design. However, the potential of composite reinforcement can only be exploited after a perfect description of their long-term properties, which are the key to a reliable design.

Fatigue tests of FRP bars are usually performed on bars with steel anchors or with bars embedded in concrete. The common difficulty of samples with steel anchors is early failure in the vicinity of the steel anchor. This phenomenon is mainly due to the stress concentration near the anchors together with the low transverse strength of the FRP bars. Anchors that function flawlessly in monotonic tensile tests are often required to be modified for cyclic loading. El Refai [1] and Noël \& Soudki [2] used modified reusable anchorage system. Its advantage is the possibility of re-use without the need to glue the bar to the anchor. However, during the cyclic loading, there is slipping of the bar in the anchor, which can be in the order of millimetres, [1. Concrete blocks for reinforcement anchoring were used in experiments by Adimi [3], Rahman [4] and Benmokrane [5]. The length of the end (anchorage) blocks must secure anchorage of samples. The sample sizes thus may be significant. The advantage, however, is the elimination of early failure of the FRP bars.

In addition to the level and nature of the load, an important factor that potentially negatively affects the long-term characteristics of the composite material is the alkaline environment, the humidity and the temperature, which generally reduce the tensile strength of FRP reinforcement [5, 6]. Even with relatively small displacements in the contact of reinforcement and concrete during cyclic loading, the surface treatment and outer layer of the matrix are impaired due to abrasions from sharp edges of concrete aggregate. Katz [7] observed a significant damage of the FRP bar surface due to the repeated friction of the reinforcement against the concrete.

Rahman et al. 4] compare the fatigue life of bare CFRP bars with the fatigue life of encased CFRP bars. The bare bars show a better fatigue life across the $\mathrm{S}-\mathrm{N}$ curve, which the authors attribute to the negative impact of the concrete environment. Noël \& Soudki [2] determined the fatigue behaviour of bare GFRP bars and beam specimens with the same GFRP bars. The bare bars showed a fatigue life of approximately one level higher than for bars embedded in the beam specimens.

\section{ExPERIMENTAL PROGRAM - TESTED SAMPLES}

GFRP bars with a $10 \mathrm{~mm}$ diameter composed of ECR fibres ( $80 \%$ by weight) and an epoxy matrix were tested to create S-N curves for bare bars and bars embedded in concrete. Bond with the concrete was provided by the silica sand-coating with a nylon winding. The short-term properties are shown in Table 1 


\begin{tabular}{ccccc}
\hline Bar diameter & $\begin{array}{c}\text { Bar diameter } \\
\text { with surface } \\
\text { treatment } \\
{[\mathrm{mm}]}\end{array}$ & $\begin{array}{c}\text { Average tensile } \\
\text { strength } \pm \mathrm{SD} \\
{[\mathrm{MPa}]}\end{array}$ & $\begin{array}{c}\text { Average Young } \\
\text { modulus } \pm \mathrm{SD} \\
{[\mathrm{GPa}]}\end{array}$ & $\begin{array}{c}\text { Average interlaminar } \\
\text { (longitudinal) strength } \\
\pm \mathrm{SD}\end{array}$ \\
\hline 10 & 11.03 & $1018.8 \pm 5.2$ & $52.2 \pm 0.3$ & $63.32 \pm 2.32$ \\
\hline
\end{tabular}

TABle 1. Properties of the reinforcement.

For more details of ongoing experimental program of GFRP bars, see Stepanek et al. 8 .

\subsection{Monotonic tensile test}

The tensile testing of FRP bars, including the subsequent evaluation, was performed according to ISO 10406-1 9. Six test specimens, $1.0 \mathrm{~m}$ in length, were fitted with steel anchors for mounting on a test device. The anchors eliminate the risk of crushing the composite bar by the transverse pressure exerted by the jaws of the device. The middle (free) part of the sample was then fitted with LVDTs. Simultaneously with the strain of the sample, the applied tensile force was read. The load was applied at a deformation rate of $3 \mathrm{~mm} / \mathrm{min}$ until the sample was completely broken. The configuration of the test and the typical way of failure is shown in Fig. 1. The obtained results are shown in Table 1, the stress-strain diagram is shown in Fig. 2 All samples were broken in an expected manner. There was a significant delamination of the individual layers of the cross-section (broomlike failure mode). However, all samples were found to have an intact core diameter of approximately $6 \mathrm{~mm}$. The creation of this core indicates a different cure of the matrix at the centre of the cross-section.

\subsection{INTERLAMinAR (LONGITUdinal) SHEAR TEST}

The purpose of interlaminar shear test was to determine the strength of matrix and/or interface between fibre/matrix. The tests were performed according to ASTM D 4475 [10. The distance between the supports was chosen with respect to the desired mode of failure, i.e. a crack parallel to the direction of the fibres (perpendicular to the load direction). A set of samples of $60 \mathrm{~mm}$ length (i.e. the distance of the theoretical supports corresponded to 5 sample diameters) was tested. The average strength in the longitudinal (interlaminar) shear is shown in Table 1 .

\section{Cyclic (fatigue) tensile tests}

The samples during fatigue tests were loaded by sinusoidal function. One of the main parameters influencing the results, i.e. the fatigue life of composite materials, is the loading frequency [11, 12. Material is heated due to energy dissipation when the frequency is high. The acceptable load frequency range is $1-10 \mathrm{~Hz}$, the recommended value is $4 \mathrm{~Hz}$, see ACI $440.3 \mathrm{R}-12$ 13. The value of $4 \mathrm{~Hz}$ was chosen for this study. Increasing the stress ratio $\mathrm{R}$ (the difference between the minimum and maximum stress) leads to a decrease of fatigue life, see 12. In ACI 440.3R-12 13] is recommended to set the stress ration equal to 0.1 .

The suggested method (c), according to ACI 440.3R12 [13, was used in this study to create the S-N curves; the stress ratio $\mathrm{R}$ is equal to 0.1 and load values are always adjusted. The samples were loaded until failure or up to maximum 2 million cycles. Three stress levels have been tested for two axially loaded test configurations: bare bars with steel anchors and embedded bars in concrete. Levels with a maximum stress value in the loading cycle equal to $40 \%, 50 \%$ and $60 \%$ of the monotonic strength were tested so far.

\subsection{Fatigue test of BARE BARS}

The first set of samples subjected to cyclic loading was tested with a similar solution to the anchors used in the monotonic tensile test. To ensure a better connection of the steel anchor with the grouting, the steel anchor body was perforated by openings (Fig. 5). However, during cyclic loading, these anchors did not work sufficiently. All samples were prematurely broken. The sample behaviour analysis had shown that the failure was accelerated by the eccentricity arising from the imperfect/inaccurate bar mounting in the anchor. This imperfection can be limited to a certain extent by inserting joints that are mutually rotated by $90^{\circ}$ (Fig. (4). The adjusted test configuration has been verified on six samples at load level $f_{\max }=$ $60 \% f_{u l t}$. With this configuration, a failure in the anchor occurred only in one case.

\subsection{FAtigue test of BARS EMBEDDED in CONCRETE}

The configuration of fatigue tests of reinforcement embedded in concrete was set according to Rahman et al. 4. The length of the end (anchorage) blocks of $500 \mathrm{~mm}$ was considered with regard to securing a sufficient bond length for the tested bars. A $100 \mathrm{~mm}$ long central block was separated from the anchor blocks using cardboard. The total length of the whole sample was $1100 \mathrm{~mm}$ (Fig. 6). To prevent splitting of concrete, the anchor blocks were compressed by steel frames. To eliminate possible eccentricities caused by the production, the sample was provided with hinges. The average compressive strength of the concrete was $63 \mathrm{MPa}$.

All samples were broken in a desirable manner, i.e. always in the middle block area. No undesired end block splitting or bond failure was observed in any of 

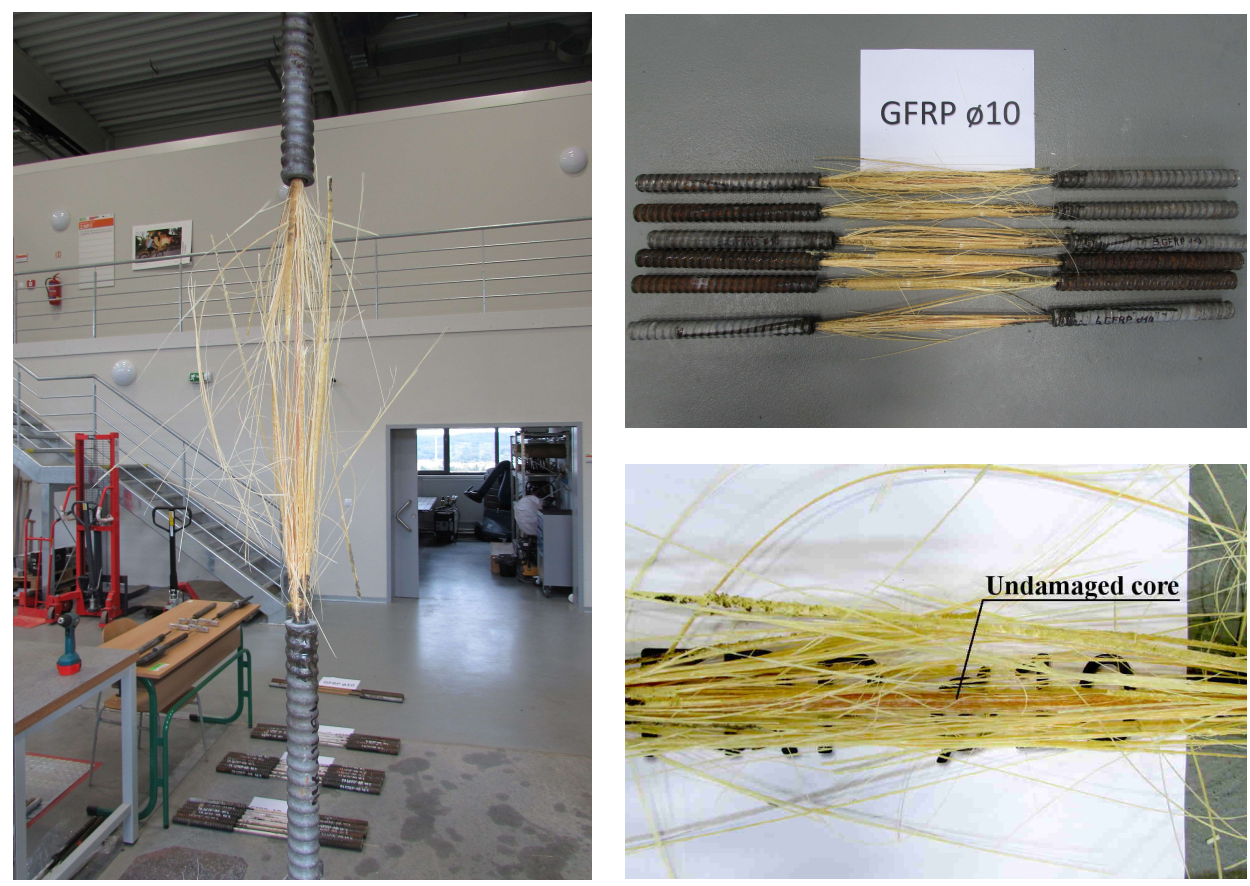

Figure 1. Failure of samples during monotonic test.

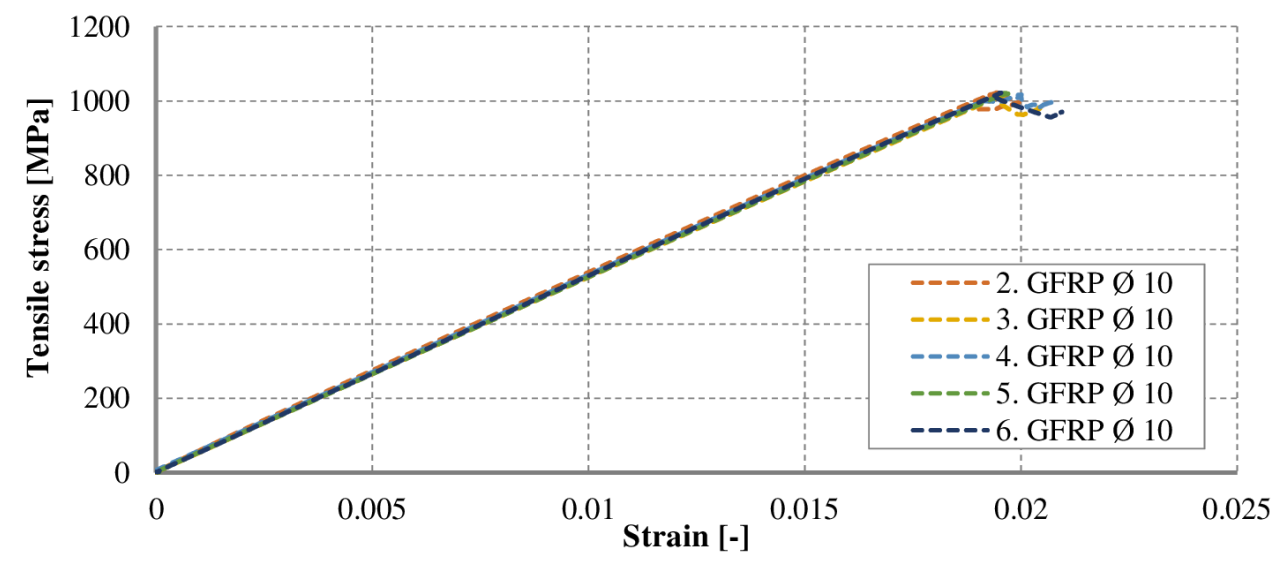

FiguRE 2. Stress-strain diagram during monotonic tensile test.

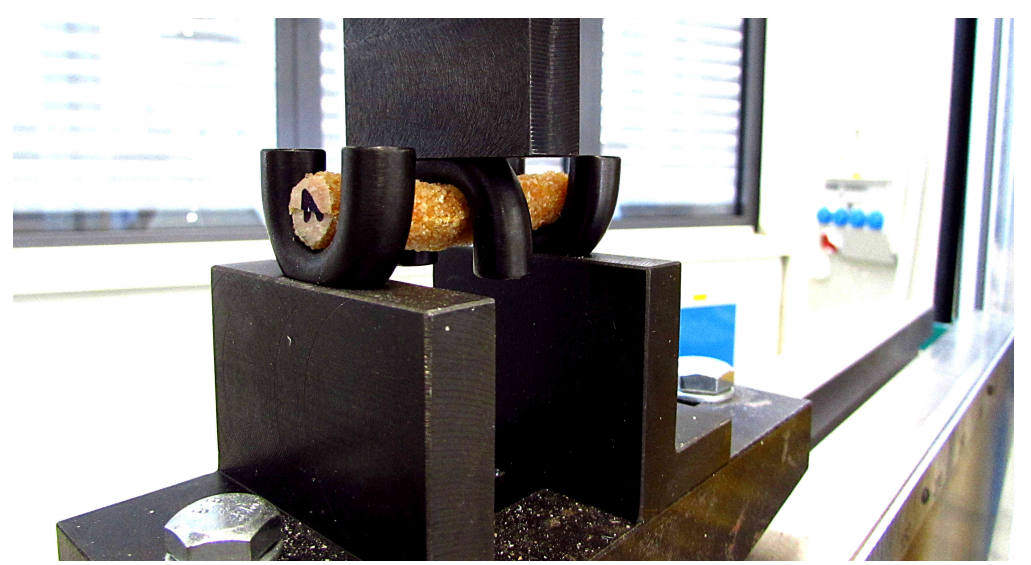

FiguRE 3. Configuration of interlaminar (longitudinal) shear test. 

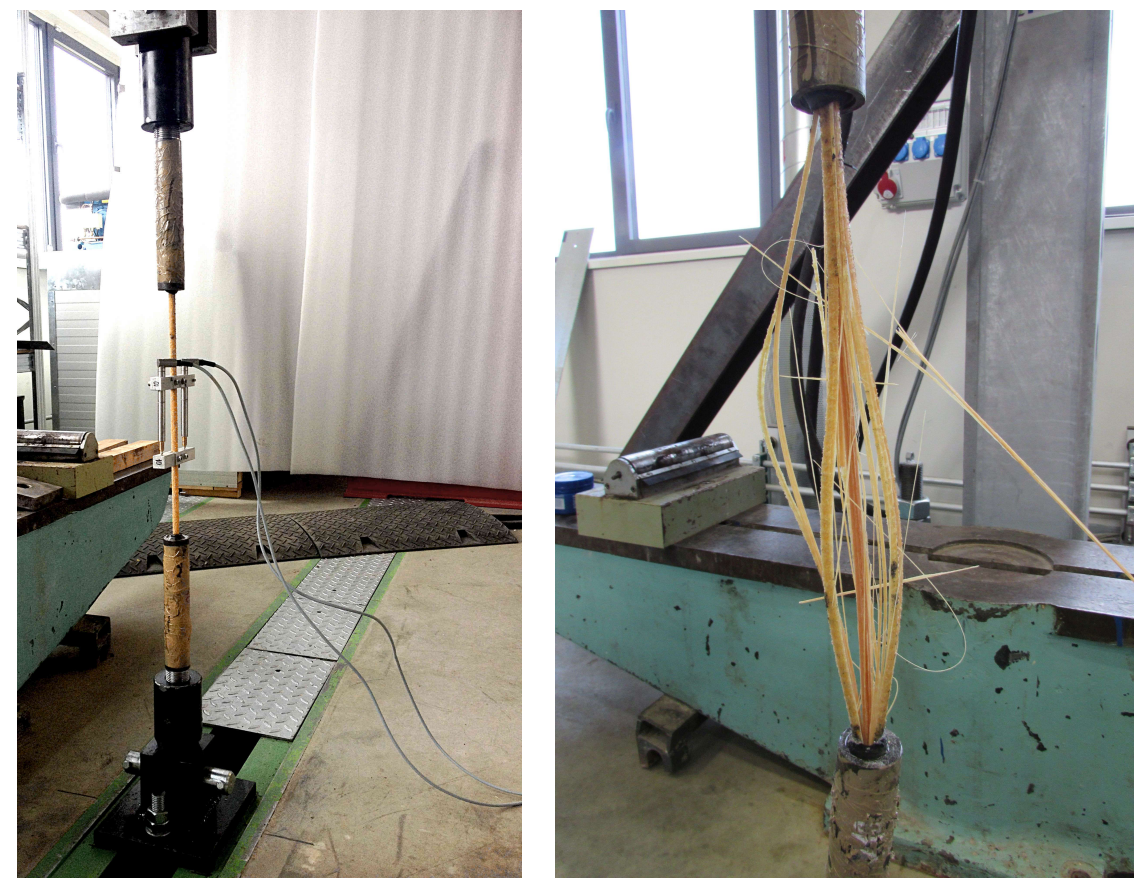

Figure 4. Cyclic test configuration with LVDTs (left), broom-like failure mode with an undamaged core (right).

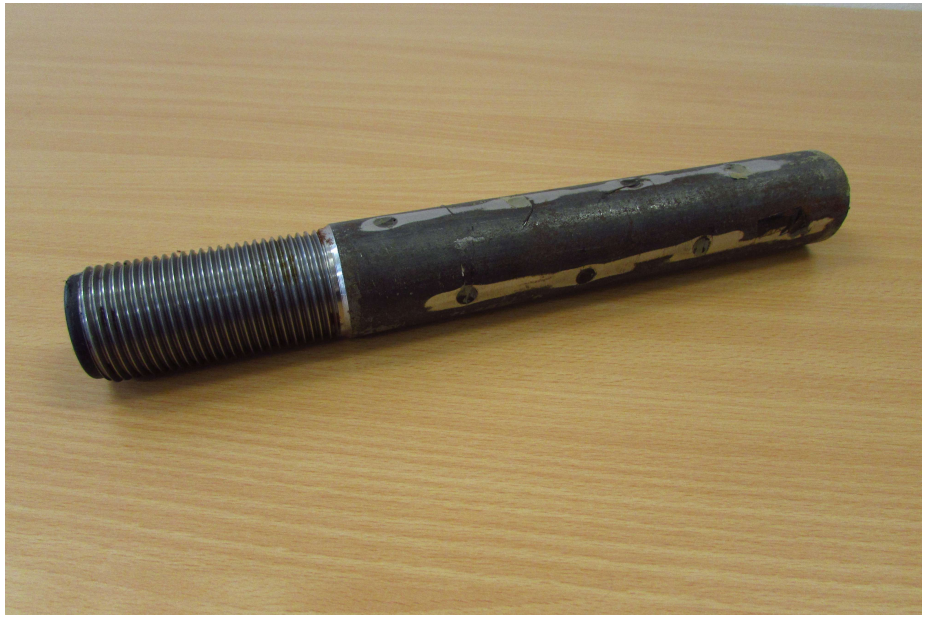

Figure 5. Anchor for a cyclic test of bare bars.

the samples. In the first phase of loading, a transverse crack in the concrete was formed at approximately half the height of the middle block due to the tensile force applied (Fig. 8). The further development of cracks in the middle block of the specimen was observed just before the reinforcement failure. A longitudinal crack was created, which in many cases led to the splitting of the middle block. This longitudinal crack was caused by the transverse pressure of the breaking bar on the concrete, where most of the samples tested broke in a broom-like failure mode.

After the test, the area of the reinforcement in contact with the concrete in the middle block was examined in more detail. The surface of the concrete or reinforcement in most cases did not show signs of macroscopic failure. However, a white residue on the surface of the concrete was evident locally (most often near the transverse crack), apparently created by the crushing of the silica sand-coating of the tested bar (Fig. 7c). The observed phenomenon occurred only in samples that were exposed to the lowest tested level of loading $\left(40 \% f_{u l t}\right)$ and, therefore, the highest number of cycles. From the observation, one can conclude that a higher number of cycles can damage the contact between the tested reinforcement and the surrounding concrete. For that reason, the next series of samples will be subjected to a deeper exploration of the surface.

It is obvious that the surrounding concrete actively (until reaching the tensile strength of the concrete) prevents reinforcement from delamination. This finding is also confirmed by the observed frequent failure of reinforcement at the unbonded length of the bar (especially at lower load levels), where the reinforcement is allowed free transverse expansion. 

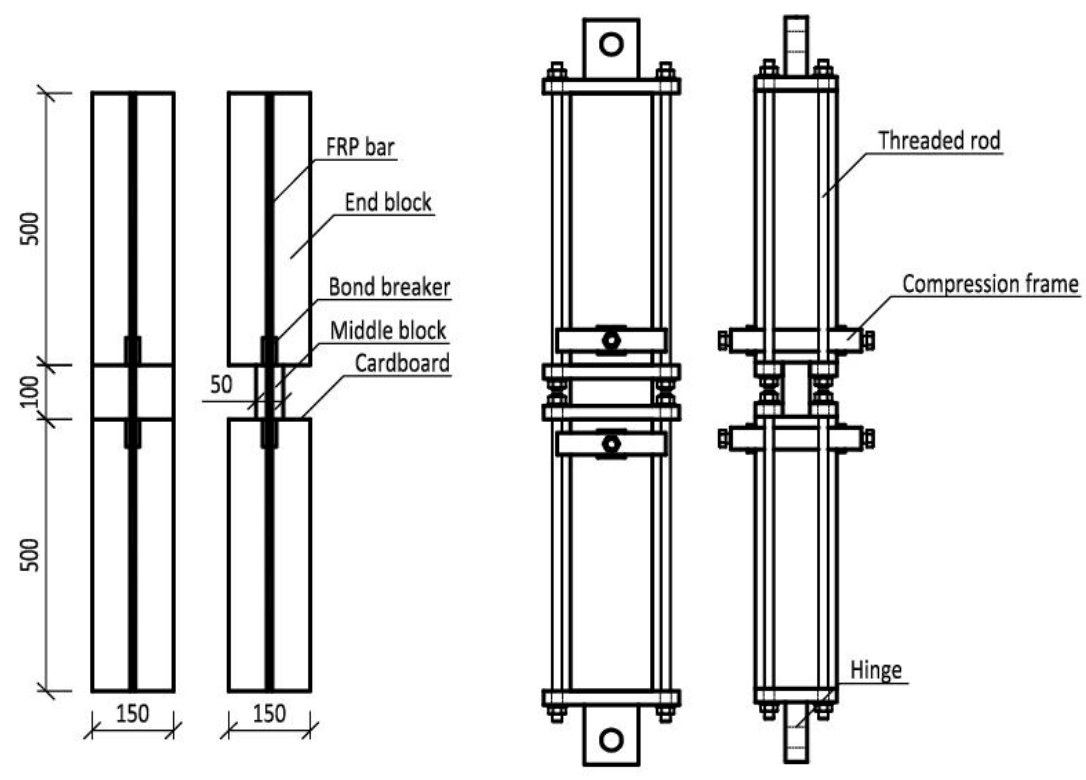

Figure 6. Bars encased in concrete - specimen geometry.

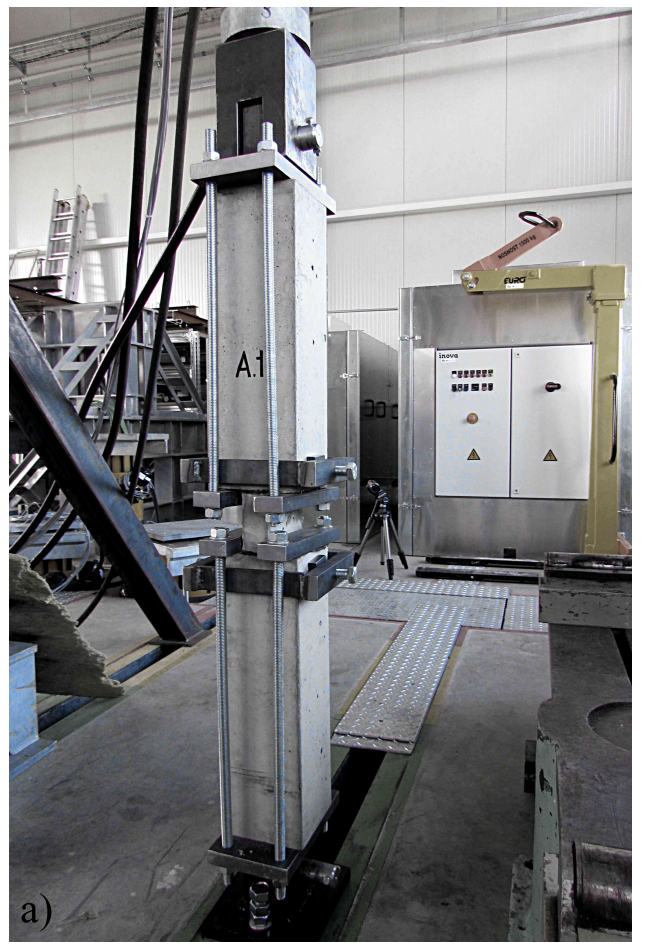

(A).

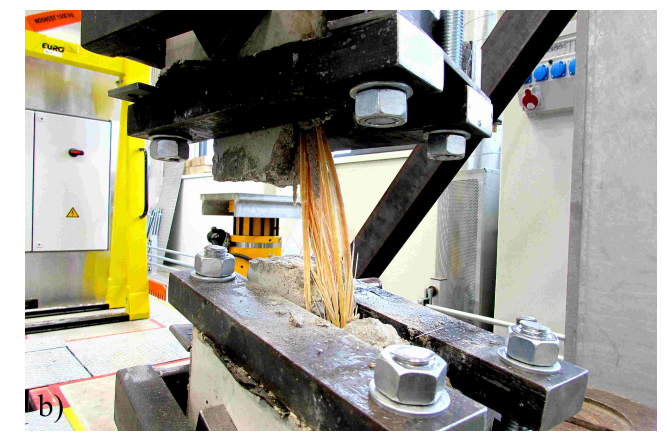

(в).

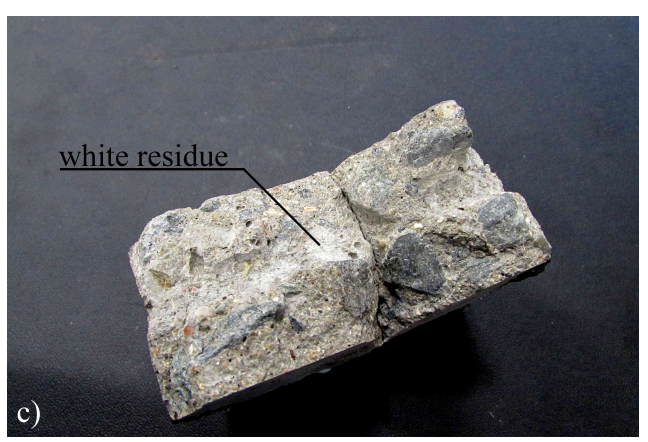

(c).

Figure 7. a) Cyclic test configuration, b) Broom-like failure mode, c) Concrete surface with a white residue. 

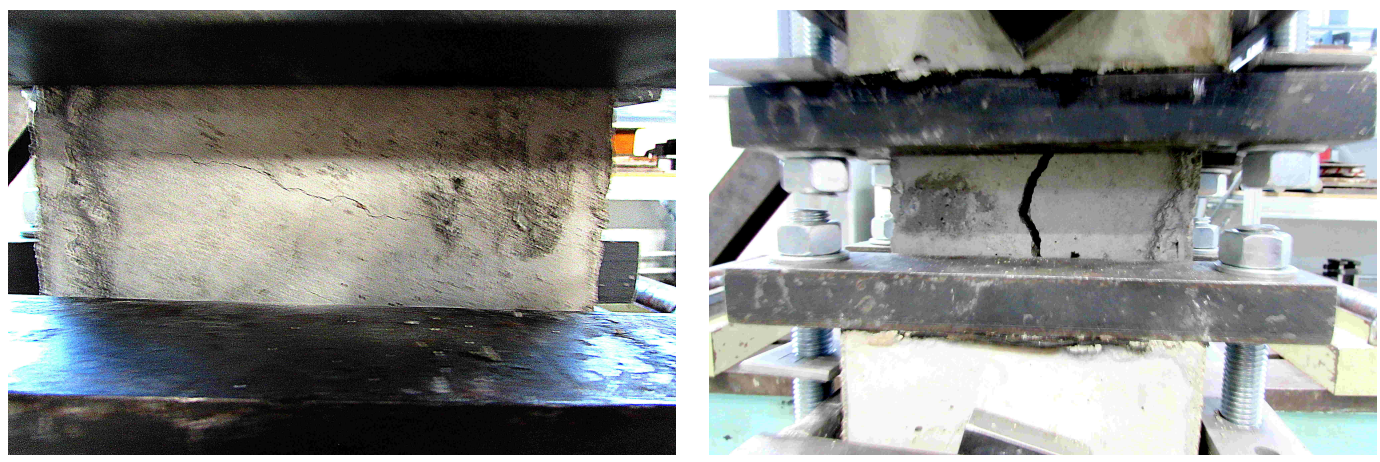

FiguRE 8. Transverse (left) and longitudinal (right) crack during cyclic loading.

\subsection{Stiffness DEgRADATION AFTER CYCLiC LOADING}

To quantify the degree of potential damage of tested samples at the beginning of the loading, an experiment was designed to determine the residual mechanical characteristics of the sample (modulus of elasticity and strength in interlaminar shear) after the first 100 cycles. Three levels of cyclic loading were verified (Table 2). The samples were loaded at a rate of $0.5 \mathrm{kN} / \mathrm{s}$ until the mean load value in the cycle was reached. After executing the set number of cycles at the frequency of $4 \mathrm{~Hz}$, the sample was unloaded to the starting position at the same speed and then loaded back to the same value. For each level, one sample was tested.

The elasticity modulus was determined by LVDT measurement before exposure to cyclic loading and after the first 100 cycles. Reduction of the modulus was not observed for any of the tested samples. This level of fatigue loading thus did not cause a failure of the fibres, which would affect stiffness of the samples.

Samples were then cut into 6 pieces of $60 \mathrm{~mm}$ for the interlaminar (longitudinal) shear test. The test was carried out in the same configuration as the reference samples (see Fig. 3). At all tested levels after 100 cycles a significant reduction of the matrix or fibre/matrix interface strength was observed (see Table 2 results).

\subsection{EFFECT OF STRESS RANGE}

The fatigue life of samples tested so far is shown in Tables 3 and 4 . Only samples that have been broken in a satisfactory manner (i.e. failure of the free part of the bare bars or failure of the bar in the central block area of the encased bars) are used to construct the S-N curve (Fig. 9).

The fatigue life of the samples increases exponentially with decreasing stress level. Equation (1) for bare bars and equation 22 for bars embedded in concrete is expressing the $\mathrm{S}-\mathrm{N}$ dependence.

$$
\begin{aligned}
& \frac{f_{\text {max }}}{f_{\text {ult }}}=1.123-0.182 \log N \\
& \frac{f_{\text {max }}}{f_{\text {ult }}}=1.026-0.135 \log N
\end{aligned}
$$

It can be seen from Fig. 9 and the equation (1) and (2) that the fatigue life of the samples embedded in concrete is higher. In the macroscopic scale, in most cases, the embedded samples did not show indications of failure of the surface treatment of the bar caused by friction between bars and concrete. In addition, the surrounding concrete prevented the broomlike failure mode of the bars. On the other hand, the fatigue life of bare bars is significantly reduced by the steel anchors. This is especially noticeable at $40 \% f_{u l t}$, load level. At this level, at most samples occurred undesirable failure near the anchors. However, fatigue life is likely to be affected at all tested levels.

Fig. 10 shows the results of the bare bars and bars embedded in concrete tests performed in this study presented along with other experiments with the same configuration and GFRP reinforcement [2, 3. Demers [12] stated that the shape of the sample influences the resulting fatigue life of the composite materials. Therefore, only the results obtained from the experiments on the samples of the GFRP bars are included here. The tests published in [2] are performed with a variable stress ratio, which affects the fatigue life, see [12. The lower fatigue life of the bare bars tested in this study indicates the negative impact of anchoring (especially at the lowest tested level). The results obtained from the tests of bars encased in concrete are comparable with other presented results (see Fig. 10p.

\section{Conclusions}

The fatigue behaviour was determined for two different configurations. For both axially loaded test configurations, S-N curves were created. These S-N curves were also compared with S-N curves of GFRP bars available in literature. From the experiments carried out so far, the following findings have been made:

(1.) The configuration of samples with encased bars in concrete seems to be appropriate for determining the fatigue life of composite reinforcement. The $500 \mathrm{~mm}$ length of the anchor block is sufficient to safely anchor the tested reinforcement. At 40\%, 50\% and $60 \% f_{u l t}$ load levels, all the samples showed a failure of the bar in the middle block or in the unbonded area. The degradation of the outer layer 


\begin{tabular}{|c|c|c|c|c|}
\hline $\begin{array}{l}\text { Maximum } \\
\text { stress } \\
\text { in the cycle }\end{array}$ & $\begin{array}{c}\text { Modulus } \\
\text { of elasticity } \\
\text { before the cyclic } \\
\text { loading } \\
\text { [GPa] }\end{array}$ & $\begin{array}{c}\text { Elasticity } \\
\text { modulus } \\
\text { after } \\
100 \text { cycles } \\
{[\mathrm{GPa}]}\end{array}$ & $\begin{array}{c}\text { Average strength } \\
\text { in interlaminar } \\
\text { (longitudinal) shear } \\
\text { at monotonic test } \\
{[\mathrm{MPa}]}\end{array}$ & $\begin{array}{c}\text { Average strength } \\
\text { in interlaminar } \\
\text { (longitudinal) shear } \\
\text { after } 100 \text { cycles } \\
{[\mathrm{MPa}]}\end{array}$ \\
\hline $40 \% f_{\text {ult }}$ & 53.43 & $53.65(+0.41 \%)$ & & $60.26(-4.83 \%)$ \\
\hline $50 \% f_{\text {ult }}$ & 52.71 & $53.48(+1.46 \%)$ & 63.32 & $59.80(-5.89 \%)$ \\
\hline $60 \% f_{u l t}$ & 52.51 & $53.19(+1.30 \%)$ & & $57.5(-10.03 \%)$ \\
\hline
\end{tabular}

TABLE 2. Comparison of mechanical properties.

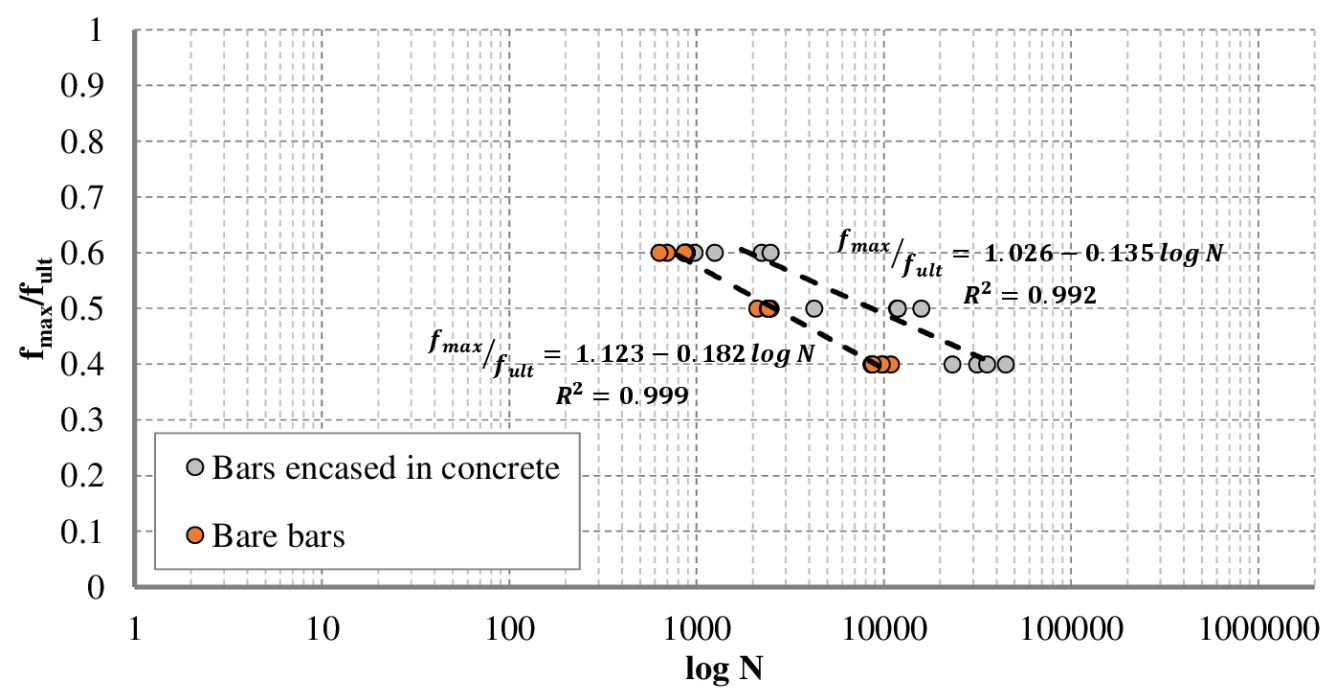

FiguRE 9. S-N diagram for tested bare GFRP bars and bars encased in concrete.

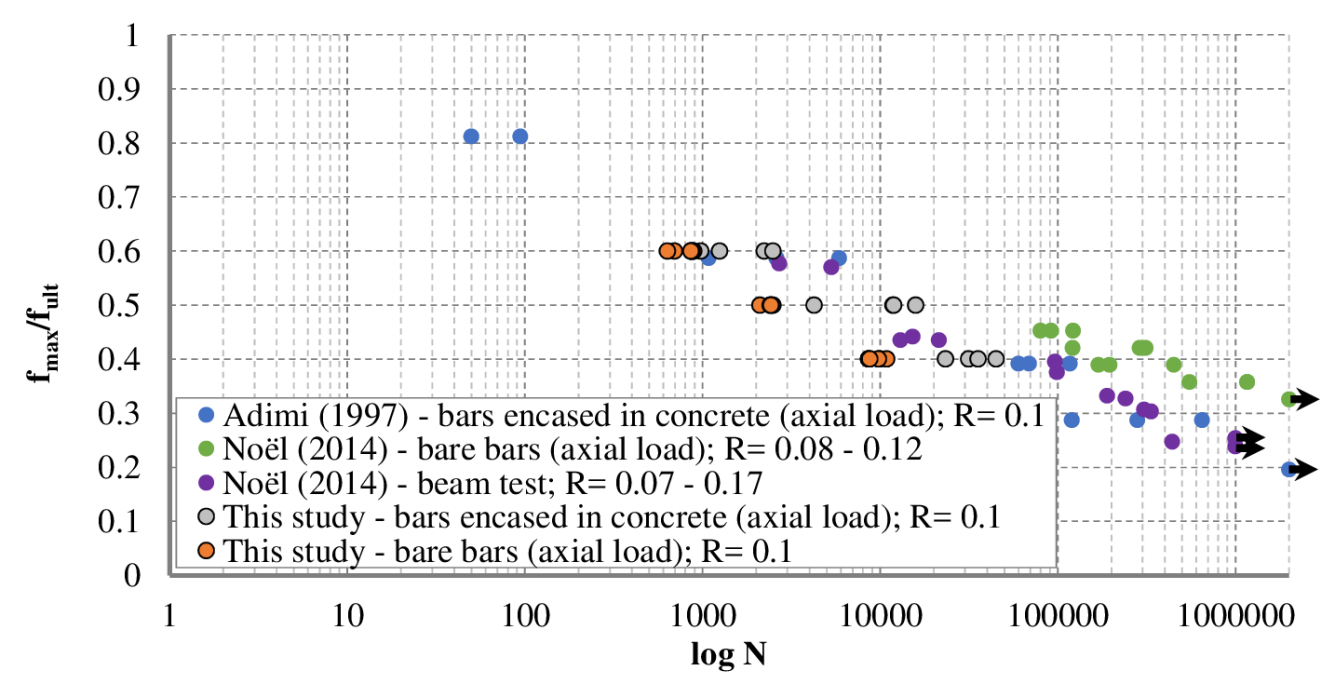

Figure 10. S-N diagram for GFRP bars. 


\begin{tabular}{|c|c|c|c|c|c|c|}
\hline \multirow{2}{*}{ Test type } & \multirow{2}{*}{ Specimen } & \multicolumn{3}{|c|}{ Stress $[\mathrm{MPa}]\left(\% f_{\text {ult }}\right)$} & \multirow{2}{*}{$\begin{array}{l}\text { Fatigue life } \\
\qquad \mathrm{N}\end{array}$} & \multirow{2}{*}{ Failure mode } \\
\hline & & Minimum & Maximum & Range & & \\
\hline \multirow{18}{*}{$\begin{array}{l}\text { Bare } \\
\text { bars }\end{array}$} & $\begin{array}{l}\text { B.GFRP.E.E } \\
\text { P.S.10-A.1 }\end{array}$ & $61(6 \%)$ & $611(60 \%)$ & $550(54 \%)$ & 695 & Broomlike \\
\hline & $\begin{array}{l}\text { B.GFRP.E.E } \\
\text { P.S.10-A.2 }\end{array}$ & $61(6 \%)$ & $611(60 \%)$ & $550(54 \%)$ & 307 & $\begin{array}{l}\text { Specimen for load } \\
\text { adjustment. } \\
\text { (Broomlike) }\end{array}$ \\
\hline & $\begin{array}{l}\text { B.GFRP.E.E } \\
\text { P.S.10-A. } 3\end{array}$ & $61(6 \%)$ & $611(60 \%)$ & $550(54 \%)$ & 634 & Broomlike \\
\hline & $\begin{array}{l}\text { B.GFRP.E.E } \\
\text { P.S.10-A.4 }\end{array}$ & $61(6 \%)$ & $611(60 \%)$ & $550(54 \%)$ & 889 & Longitudinal cracks \\
\hline & $\begin{array}{l}\text { B.GFRP.E.E } \\
\text { P.S.10-A.5 }\end{array}$ & $61(6 \%)$ & $611(60 \%)$ & $550(54 \%)$ & 870 & Broomlike \\
\hline & $\begin{array}{l}\text { B.GFRP.E.E } \\
\text { P.S.10-A. } 6\end{array}$ & $61(6 \%)$ & $611(60 \%)$ & $550(54 \%)$ & 861 & Anchor \\
\hline & $\begin{array}{l}\text { B.GFRP.E.E } \\
\text { P.S.10-B.1 }\end{array}$ & $51(5 \%)$ & $509(50 \%)$ & $458(45 \%)$ & 1571 & $\begin{array}{l}\text { Specimen for load } \\
\text { adjustment. } \\
\text { (Broomlike) }\end{array}$ \\
\hline & $\begin{array}{l}\text { B.GFRP.E.E } \\
\text { P.S.10-B.2 }\end{array}$ & $51(5 \%)$ & $509(50 \%)$ & $458(45 \%)$ & 2483 & Longitudinal cracks \\
\hline & $\begin{array}{l}\text { B.GFRP.E.E } \\
\text { P.S.10-B.3 }\end{array}$ & $51(5 \%)$ & $509(50 \%)$ & $458(45 \%)$ & 2426 & Longitudinal cracks \\
\hline & $\begin{array}{l}\text { B.GFRP.E.E } \\
\text { P.S.10-B.4 }\end{array}$ & $51(5 \%)$ & $509(50 \%)$ & $458(45 \%)$ & 2104 & Longitudinal cracks \\
\hline & $\begin{array}{l}\text { B.GFRP.E.E } \\
\text { P.S.10-B.5 } \\
\end{array}$ & $51(5 \%)$ & $509(50 \%)$ & $458(45 \%)$ & 2398 & Broomlike \\
\hline & $\begin{array}{l}\text { B.GFRP.E.E } \\
\text { P.S.10-B.6 } \\
\end{array}$ & $51(5 \%)$ & $509(50 \%)$ & $458(45 \%)$ & 2422 & Broomlike \\
\hline & $\begin{array}{l}\text { B.GFRP.E.E } \\
\text { P.S.10-C.1 }\end{array}$ & $41(4 \%)$ & $408(40 \%)$ & $367(36 \%)$ & 9925 & $\begin{array}{c}\text { Anchor }+ \text { longitudinal } \\
\text { crack }\end{array}$ \\
\hline & $\begin{array}{l}\text { B.GFRP.E.E } \\
\text { P.S.10-C.2 }\end{array}$ & $41(4 \%)$ & $408(40 \%)$ & $367(36 \%)$ & 8611 & Longitudinal cracks \\
\hline & $\begin{array}{l}\text { B.GFRP.E.E } \\
\text { P.S.10-C. } 3 \\
\end{array}$ & $41(4 \%)$ & $408(40 \%)$ & $367(36 \%)$ & 10899 & Longitudinal cracks \\
\hline & $\begin{array}{l}\text { B.GFRP.E.E } \\
\text { P.S.10-C.4 }\end{array}$ & $41(4 \%)$ & $408(40 \%)$ & $367(36 \%)$ & 9758 & Longitudinal crack \\
\hline & $\begin{array}{l}\text { B.GFRP.E.E } \\
\text { P.S.10-C.5 }\end{array}$ & $41(4 \%)$ & $408(40 \%)$ & $367(36 \%)$ & 8614 & Longitudinal cracks \\
\hline & $\begin{array}{l}\text { B.GFRP.E.E } \\
\text { P.S.10-C.6 }\end{array}$ & $41(4 \%)$ & $408(40 \%)$ & $367(36 \%)$ & 8752 & $\begin{array}{c}\text { Anchor }+ \text { longitudinal } \\
\text { crack }\end{array}$ \\
\hline
\end{tabular}




\begin{tabular}{|c|c|c|c|c|c|c|}
\hline \multirow{2}{*}{ Test type } & \multirow{2}{*}{ Specimen } & \multicolumn{3}{|c|}{ Stress $[\mathrm{MPa}]\left(\% f_{\text {ult }}\right)$} & \multirow{2}{*}{$\begin{array}{l}\text { Fatigue life } \\
\mathrm{N}\end{array}$} & \multirow{2}{*}{ Failure mode } \\
\hline & & Minimum & Maximum & Range & & \\
\hline \multirow{12}{*}{$\begin{array}{c}\text { Bars } \\
\text { embedded } \\
\text { in concrete }\end{array}$} & $\begin{array}{c}\text { C.GFRP.E.E } \\
\text { P.S.10-A.1 } \\
\end{array}$ & $61(6 \%)$ & $611(60 \%)$ & $550(54 \%)$ & 1249 & Broomlike \\
\hline & $\begin{array}{l}\text { C.GFRP.E.E } \\
\text { P.S.10-A.2 }\end{array}$ & $61(6 \%)$ & $611(60 \%)$ & $550(54 \%)$ & 975 & $\begin{array}{c}\text { Broomlike } \\
\text { (unbonded length) }\end{array}$ \\
\hline & $\begin{array}{l}\text { C.GFRP.E.E } \\
\text { P.S.10-A.3 } \\
\end{array}$ & $61(6 \%)$ & $611(60 \%)$ & $550(54 \%)$ & 2226 & Longitudinal cracks \\
\hline & $\begin{array}{l}\text { C.GFRP.E.E } \\
\text { P.S.10-A.4 }\end{array}$ & $61(6 \%)$ & $611(60 \%)$ & $550(54 \%)$ & 2489 & Broomlike \\
\hline & $\begin{array}{l}\text { C.GFRP.E.E } \\
\text { P.S.10-B.1 }\end{array}$ & $51(5 \%)$ & $509(50 \%)$ & $458(45 \%)$ & 15871 & $\begin{array}{c}\text { Broomlike } \\
\text { (unbonded length) }\end{array}$ \\
\hline & $\begin{array}{l}\text { C.GFRP.E.E } \\
\text { P.S.10-B.2 }\end{array}$ & $51(5 \%)$ & $509(50 \%)$ & $458(45 \%)$ & 4243 & $\begin{array}{c}\text { Broomlike } \\
\text { (unbonded length) }\end{array}$ \\
\hline & $\begin{array}{l}\text { C.GFRP.E.E } \\
\text { P.S.10-B.3 }\end{array}$ & $51(5 \%)$ & $509(50 \%)$ & $458(45 \%)$ & 11785 & $\begin{array}{c}\text { Broomlike } \\
\text { (unbonded length) }\end{array}$ \\
\hline & $\begin{array}{l}\text { C.GFRP.E.E } \\
\text { P.S.10-B.4 }\end{array}$ & $51(5 \%)$ & $509(50 \%)$ & $458(45 \%)$ & 11900 & Broomlike \\
\hline & $\begin{array}{l}\text { C.GFRP.E.E } \\
\text { P.S.10-C.1 }\end{array}$ & $41(4 \%)$ & $408(40 \%)$ & $367(36 \%)$ & 23301 & $\begin{array}{c}\text { Broomlike } \\
\text { (unbonded length) }\end{array}$ \\
\hline & $\begin{array}{l}\text { C.GFRP.E.E } \\
\text { P.S.10-C. } 2\end{array}$ & $41(4 \%)$ & $408(40 \%)$ & $367(36 \%)$ & 31508 & Longitudinal cracks \\
\hline & $\begin{array}{l}\text { C.GFRP.E.E } \\
\text { P.S.10-C.3 }\end{array}$ & $41(4 \%)$ & $408(40 \%)$ & $367(36 \%)$ & 44876 & $\begin{array}{c}\text { Broomlike } \\
\text { (unbonded length) }\end{array}$ \\
\hline & $\begin{array}{l}\text { C.GFRP.E.E } \\
\text { P.S.10-C.4 }\end{array}$ & $41(4 \%)$ & $408(40 \%)$ & $367(36 \%)$ & 35610 & $\begin{array}{c}\text { Broomlike } \\
\text { (unbonded length) }\end{array}$ \\
\hline
\end{tabular}

TABLE 4. Tested specimens - fatigue life.

of the bar caused by friction with the surrounding concrete was observed only to a small extent and only in the $40 \% f_{u l t}$ samples. The cover layer of the concrete in the middle part of the sample prevented the early breakage of the reinforcement by broomlike failure mode.

(2.) The fatigue life of bars embedded in concrete is higher than fatigue life of the bare bars. However, it is likely that the chosen anchorage method has a negative influence on the fatigue life of bare samples in this study. In case of imperfect direct placement of the bar in the anchor, a combined load axial load and flexure will occur.

(3.) All tested levels show the evident failure of matrix or fibre/matrix interface (if the load level is $60 \%$ $f_{\text {ult }}$ by more than $10 \%$ ) after the first 100 cycles. However, the modulus of elasticity was not adversely affected. It can, therefore, be assumed that in the case of test load levels, there is no failure of the fibres.

\section{ACKNOWLEDGEMENTS}

The presented results were obtained with the financial support of project TH03020067 "FRP reinforcement with increased reliability and durability against fatigue loads" and FAST-J-18-5224 "Interlaminar shear test of FRP bars for quick and effective evaluation of product quality and determination of degradation rate".

\section{REFERENCES}

[1] A. El Refai. Durability and fatigue of basalt fiber-reinforced polymer bars gripped with steel wedge anchors. Journal of Composites for Construction 17:111, 2013. DOI:10.1061/(ASCE)CC.1943-5614.0000417.

[2] M. Noël, K. Soudki. Fatigue behavior of GFRP reinforcing bars in air and in concrete. Journal of Composites for Construction 18(5):1-8, 2014. DOI:10.1061/(ASCE)CC.1943-5614.0000468.

[3] M. R. Adimi, B. Benmokrane, H. A. Rahman. Fatigue behaviour of GFRP bars embedded in concrete. In Annual Conference of the Canadian Society for Civil Engineering, vol. 6, pp. 121-130. 1997.

[4] A. H. Rahman, M. R. Adimi, B. Benmokrane. Fatigue behaviour of FRP reinforcements encased in concrete. Advanced Composite Materials in Bridges and Structures 2:691-698, 1996.

[5] B. Benmokrane, F. Elgabbas, E. Ahmed, P. Cousin. Characterization and comparative durability study of glass/vinylester, basalt/vinylester, and basalt/epoxy FRP bars. Journal of Composites for Construction 19:112, 2015. DOI:10.1061/(ASCE)CC.1943-5614.0000564 
[6] F. Girgle, L. Bodnárová, O. Januš, V. Kostiha. Influence of alkalinity and ambient temperature on long-term properties of GFRP reinforcement. In Special Concrete and Composites 2017, vol. 760 of Key Engineering Materials, pp. 213-218. Trans Tech Publications, 2018. DOI:10.4028/www.scientific.net/KEM.760.213

[7] A. Katz. Bond to concrete of FRP rebars after cyclic loading. Journal of Composites for Construction 4(3):137-144, 2000. DOI:10.1061/(ASCE)1090-0268(2000)4:3(137)

[8] P. Štěpánek, O. Januš, F. Girgle, et al. Long term strength of internal GFRP reinforcement by alkaline, temperature and cyclic loading. In XIV International Conference on Building Pathology and Constructions Repair (CINPAR 2018), vol. 11, pp. 12-19. 2018. DOI:10.1016/j.prostr.2018.11.003

[9] ISO 10406-1:2015 - Fibre-reinforced polymer (FRP) reinforcement of concrete - Test methods - Part 1: FRP bars and grids. Standard, American Concrete Institute, 2008.
[10] ASTM D4475-02 - Standard test method for apparent horizontal shear strength of pultruded reinforced plastic rods by the short-beam method. Standard, American Concrete Institute, 2016.

[11] M. R. Adimi, A. H. Rahman, B. Benmokrane. New method for testing fiber-reinforced polymer rods under fatigue. Journal of Composites for Construction 4(4):206213, 2000. DOI:10.1061/(ASCE)1090-0268(2000)4:4(206)

[12] C. Demers. Tension-tension axial fatigue of E-glass fiber-reinforced polymeric composites: Tensile fatigue modulus. Construction and Building Materials 12:51-58, 1998. DOI:10.1016/S0950-0618(97)00059-7.

[13] ACI 440.3R-12 - Guide test methods for fibre-reinforced polymers (FRPs) for reinforcing or rtrengthening concrete structures. Standard, American Concrete Institute, 2012. 